\section{Gategory}

Synthesis of Heterocycles

\section{Key words}

\section{furans}

palladium catalysis

cycloreduction

SYNFACThath

C. H. OH, * H. M. PARK, D. I. PARK (HANYANG UNIVERSITY, SEOUL, KOREA)

Highly Functionalized and Stereocontrolled Syntheses of 2-(2-Methylenecycloalkyl)-furan Derivatives by Pd-

Catalyzed Cycloreduction

Org. Lett. 2007, 9, 1191-1193.

\title{
Pd-Catalyzed Reductive Double Cyclization of Yne-enynals to Furans
}

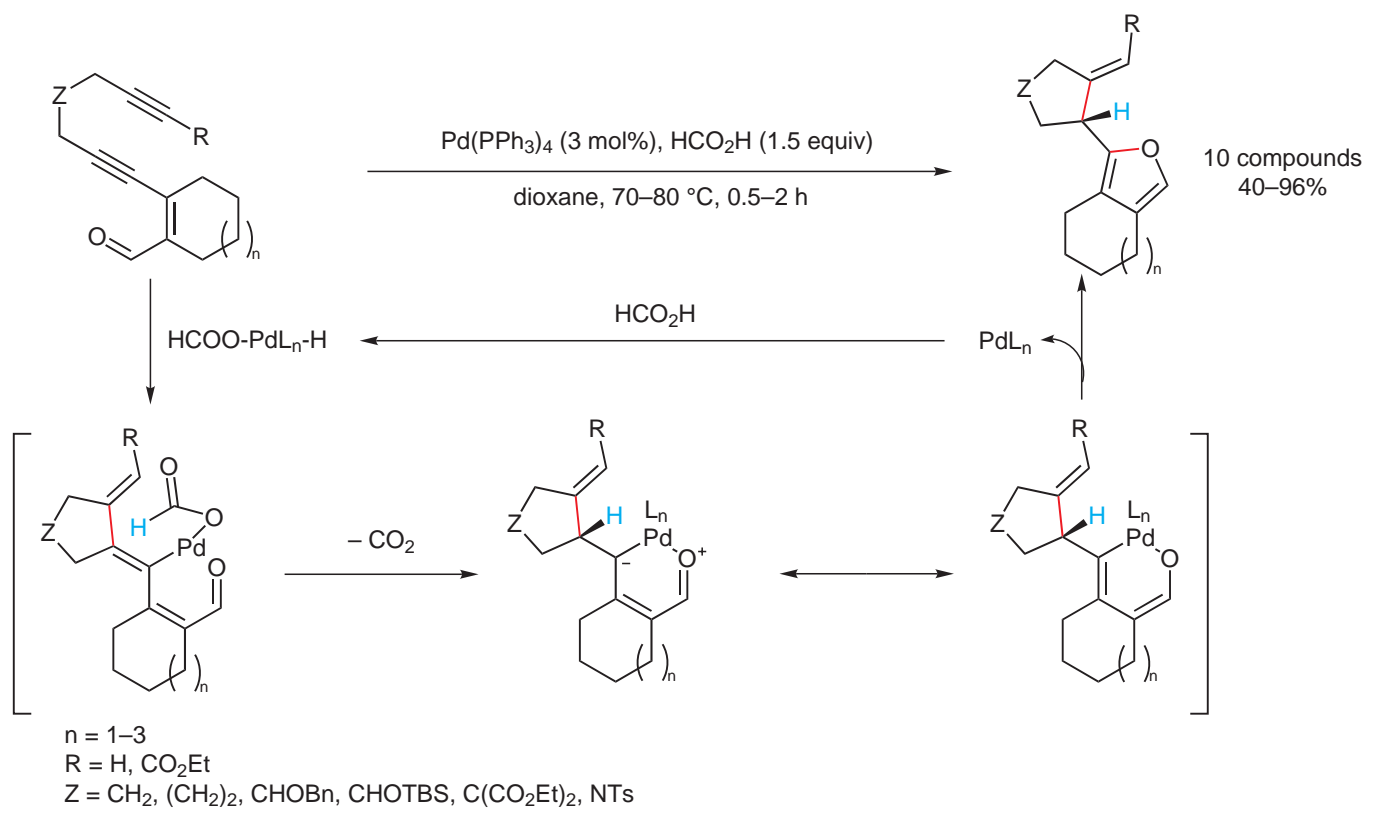

Significance: A palladium-catalyzed reductive double cyclization of conjugated enynals bearing an alkyne tether leading to 2-(2-methylenecycloalkyl)-furans in moderate to excellent yields is reported. Hydropalladation of the internal triple bond with an in situ generated $\mathrm{PdOCOH}$ species is proposed as a mechanistic rationale. This is followed by carbonyl oxygen attack of the palladium nucleus and release of $\mathrm{CO}_{2}$ during a hydride transfer reaction.
Comment: Due to their widespread occurrence in nature and their biological activities, the synthesis of furans has received increasing synthetic attention recently (see review below). Attractive transition-metal-catalyzed furan syntheses have been developed using, e.g., copper(I) salts (N. T. Patil, H. Wu, Y. Yamamoto J. Org. Chem. 2005, 70, 4531-4534) and gold(III) catalysis (T. Yao, X. Zhang, R. C. Larock J. Am. Chem. Soc. 2004, 126, 11164-11165). The herein reported method highlights an interesting double $\mathrm{C}-\mathrm{C}$ bond-forming process which furnishes condensed furan systems, thus offering a reaction from simple precursors to systems of considerable complexity. Further investigation of scope and limitations would be of interest.

Review: M. Maier Organic Synthesis Highlights I/; H. Waldmann, Ed.; VCH Weinheim: Germany, 1995, 231-242.

SYNFACTS Contributors: Victor Snieckus, Heiko Scharl Dol: 10.1055/s-2007-968574; Reg-No.: V05007SF 